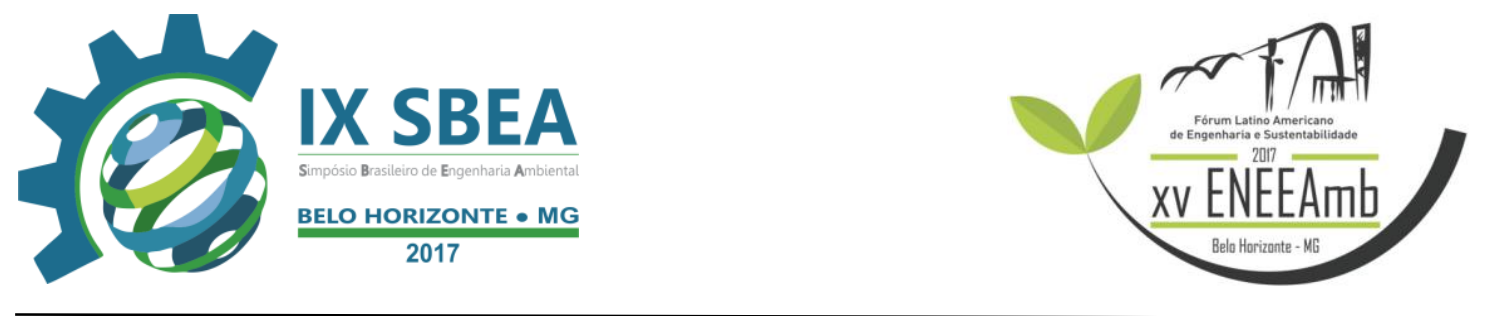

ÁREA TEMÁTICA: EDUCAÇÃO AMBIENTAL

\title{
A importância da Educação Ambiental Informal na formação básica de crianças: projeto realizado no Instituto Pe. João Emílio na cidade de Juiz de Fora
}

Fernanda Deister Moreira - fernanda.deister@engenharia.ufjf.br

Graduanda em Engenharia Ambiental e Sanitária da Universidade Federal de Juiz de Fora (UFJF) - Presidente da ONG Engenheiros Sem Fronteiras - Núcleo Juiz de Fora

Luana Queiroz Pilate-1uana.pilate@engenharia.ufjf.br

Graduanda em Engenharia Ambiental e Sanitária da Universidade Federal de Juiz de Fora (UFJF) - Diretoria do departamento de Comunicação e Marketing da ONG Engenheiros sem Fronteiras- Núcleo Juiz de Fora

Ludymila Mafra de Almeida Dias- ludymila.mafra@engenharia.ufjf.br Graduanda em Engenharia Ambiental e Sanitária da Universidade Federal de Juiz de Fora (UFJF) - Gestora do departamento de Qualidade da ONG Engenheiros sem Fronteiras- Núcleo Juiz de Fora

Maria Helena Rodrigues Gomes-mariahelena.gomes@ufjf.edu.br Docente do Departamento de Engenharia Sanitária e Ambiental da Universidade Federal de Juiz de Fora (UFJF) 


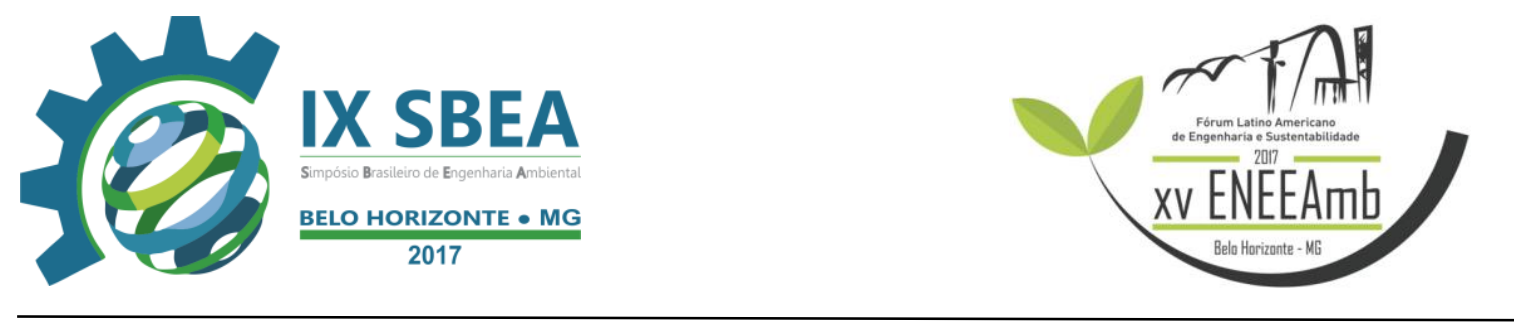

\section{RESUMO}

A importância da educação ambiental frente à conservação do meio ambiente e do bem-estar social, aliados aos valores da ONG Engenheiros Sem Fronteiras - Núcleo Juiz de Fora (ESF - JF), que abrange responsabilidade socioambiental e a busca por transformação social por meio da Engenharia, desencadeou um projeto de educação ambiental que foi desenvolvido com 100 crianças do Instituto Pe. João Emílio. O trabalho foi planejado e realizado por membros do $\mathrm{ESF}$ - JF, as atividades ocorreram durante uma semana, sendo que cada dia eram relacionadas a um tema dentro da temática principal de meio ambiente. Foi possível perceber um grande envolvimento das crianças com as atividades propostas e concluiu-se que a Educação Ambiental não formal com crianças é uma via para construir um conjunto de hábitos que valorizem as práticas de responsabilidade socioambiental.

Palavras-chave: Educação Ambiental não formal, responsabilidade socioambiental

\section{INTRODUÇÃO/OBJETIVO}

A Educação Ambiental (E.A), assim como dispõe a Lei Federal n 9.795 (BRASIL, 1999) surge com o propósito de construir/reforçar valores sociais, atitudes e competências voltadas para a conservação do meio ambiente, bem de uso comum do povo, essencial à sadia qualidade de vida e sua sustentabilidade.

A responsabilidade pela educação ambiental não é apenas das instituições que oferecem a educação formal, mas também daquelas que fornecem a educação não formal, como as Organizações não governamentais (ONGs), associação de moradores e organizações de cidadãos. (REIGADA \& REIS, 2004). A Educação Ambiental não formal prioriza a potencialização do indivíduo e de pequenos grupos e da proteção e melhoria na qualidade do ambiente (SORRENTINO apud REIGADA \& REIS, 2004).

O foco da educação ambiental com crianças vem de uma necessidade percebida na pedagogia da Educação Infantil descrita como carente em alguns quesitos, devido a certas privações do atual sistema de educação, como na área socioafetiva, do espaço físico, do tempo livre e a da natureza (GARCIA apud ELALI, 2003). Assim, associar as 
características do ambiente e a relação do espaço construído e natural é uma forma de garantir a criança consciência do seu entorno e de si próprio (ELALI, 2003).

O Engenheiros sem Fronteiras (ESF) é uma ONG que surgiu na França na década de 1980. Atualmente há mais de 60 grupos espalhados pelo mundo que buscam a transformação social por meio da engenharia. No Brasil, a ONG é recente, tendo se estabilizado em 2009 com sede em Viçosa (MG), contando atualmente com mais de 60 núcleos espalhados por 10 estados do país. (ESF - BRASIL, 2017)

Em Juiz de Fora (ESF-JF), o ESF começou suas atividades em novembro de 2015, adquirindo cada vez mais reconhecimento através dos projetos realizados. Um dos valores do núcleo é a responsabilidade socioambiental e dentro dessa vertente buscou-se atuar/realizar projetos de E.A e um deles foi realizado junto às crianças atendidas pelo Instituto Padre João Emílio em Juiz de Fora

Partindo da importância da E.A aliado aos valores do ESF-JF que também engloba responsabilidade socioambiental, o presente trabalho foi elaborado buscando contribuir no amplo processo educativo sobre consciência ambiental, trabalhando conceitos e ações relacionado ao tema.

\section{METODOLOGIA}

A escolha do Instituto João Emílio se baseou no fato de que este recebe em contra turno 100 crianças, entre 6 e 11 anos, de escolas da rede municipal e da rede estadual de Juiz de Fora, sendo um bom representativo da realidade do conhecimento sobre a tema de meio ambiente.

O planejamento do projeto incluiu um alinhamento das atividades a serem realizadas, junto à coordenação pedagógica da instituição. Assim, definiu-se uma semana de interação com as crianças, entre 20 e 24 de março de 2017, para realizar as tarefas e dinâmicas correlacionadas à temática ambiental.

Os métodos utilizados para as atividades foram baseados em atividades de ensino infantil e fundamental, como desenhos, elaboração de cartazes, oficina de brinquedos e brincadeiras abordando a consciência ambiental das crianças. 
Para a realização do projeto, os membros da ONG Engenheiros sem Fronteiras - Juiz de Fora - receberam treinamento de alunos da graduação de Engenharia Ambiental e Sanitária da Universidade Federal de Juiz de Fora (UFJF), sobre os respectivos assuntos abordados, meio ambiente e preservação, resíduos sólidos e recursos hídricos, ampliando seus conhecimentos no assunto a fim de ensinar e orientar de forma satisfatória as crianças atingidas pelo projeto.

\section{RESULTADOS E DISCUSSÃO}

No primeiro dia foi abordado o tema de Meio Ambiente e Preservação, de forma que as crianças, separadas por faixa etária, pudessem expressar seus conhecimentos prévios do assunto e para que os tutores pudessem, posteriormente, trabalhar os conceitos de forma mais direcionada. Como dinâmica, foi solicitado que cada criança fizesse um desenho expressando seu entendimento/conhecimento sobre o significado da palavra meio ambiente (Figura 1) e também foram produzidos vídeos, com o intuito de interagir, introduzir e contextualizar a temática abrangida em toda a semana.

De acordo com Pedrini et al. (2010) as crianças tendem a perceber a concepção de meio ambiente em seis formas diferentes: natureza intocável; recurso a ser gerenciado e explorado pela sociedade; local degradado pela poluição; lugar a ser vivido; lugar em que há interdependência entre os seres vivos e não vivos - planeta como matriz de vida; e proposta comunitária.

Os desenhos observados, em sua maioria, remetiam aos conceitos de natureza intocável e planeta como matriz de vida, com interdependência dos seres vivos e não vivos. 

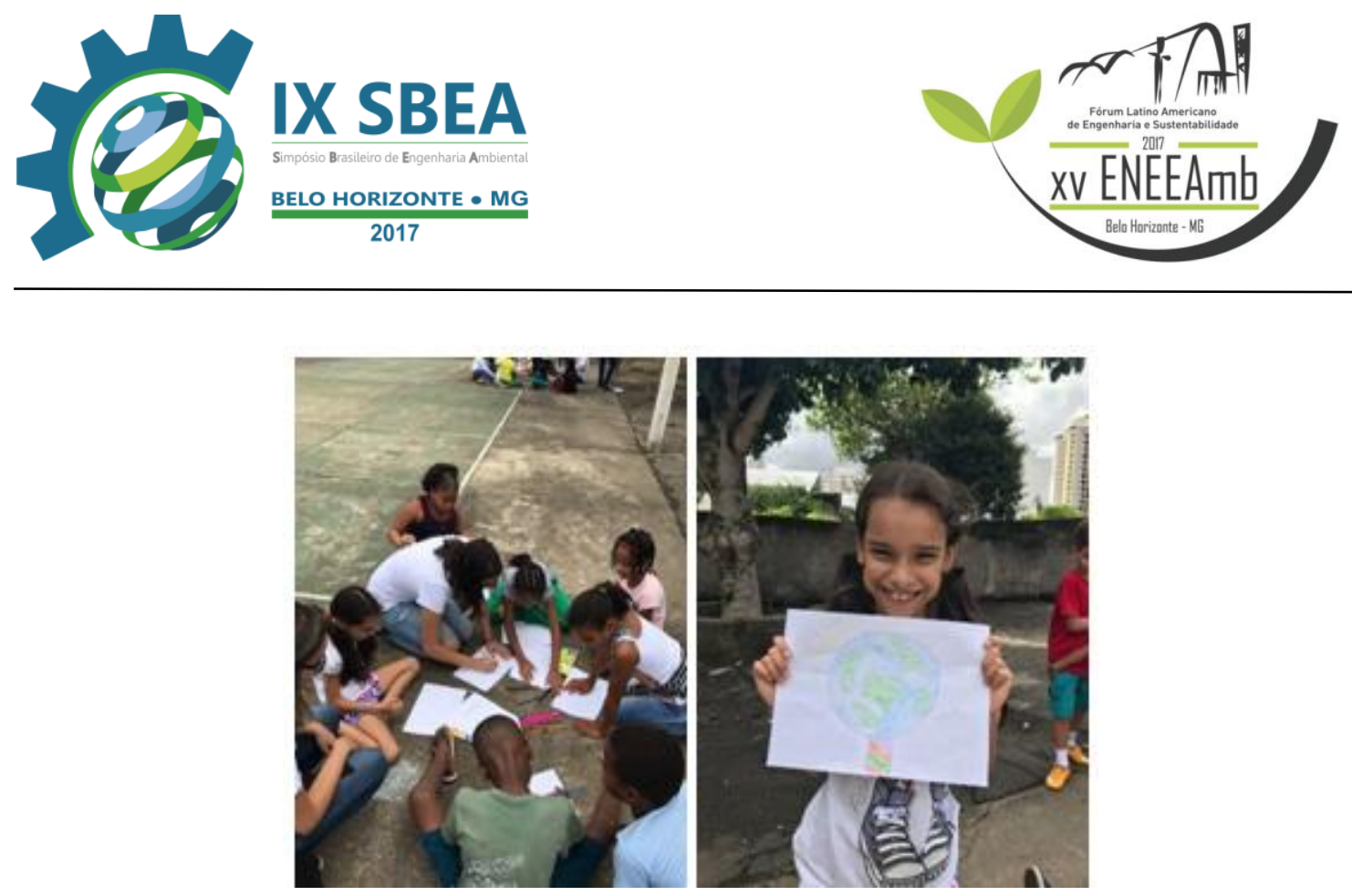

Figura 1: Confecção de cartazes alusivos ao conceito de meio ambiente.

Fonte: arquivo Engenheiros sem Fronteiras - JF

Já o segundo dia, contou com o tema Lixo e Reciclagem, sendo abordados a importância da separação, da disposição correta dos resíduos sólidos e os impactos ambientais causados no meio ambiente com o descarte incorreto dos resíduos, como, por exemplo, a contaminação do solo e do lençol freático. Além disso, foi proposta uma brincadeira interativa, na qual as crianças recebiam cartões com figuras de resíduos como garrafas, latas, cascas de frutas; e posteriormente, depositavam esses "materiais" no espaço correto das caixas coletoras (Figura 2). Essa atividade teve como objetivo fixar as cores das lixeiras da coleta seletiva e testar os ensinamentos anteriores. Para complementar de forma lúdica, foi distribuída uma atividade para colorir, também abrangendo o assunto de destinação correta de resíduos.

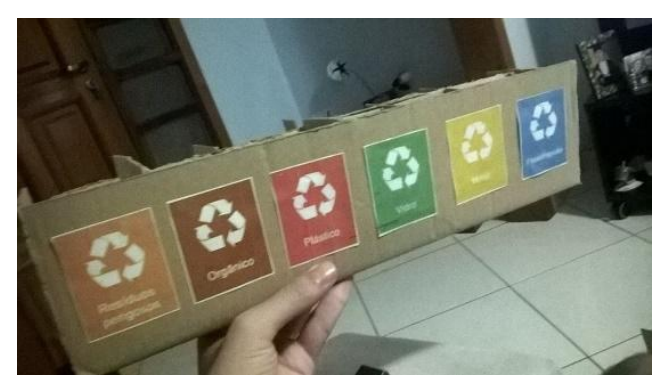

Figura 2: Modelo de caixa coletora utilizada na segunda atividade Fonte: arquivo Engenheiros sem Fronteiras - JF 


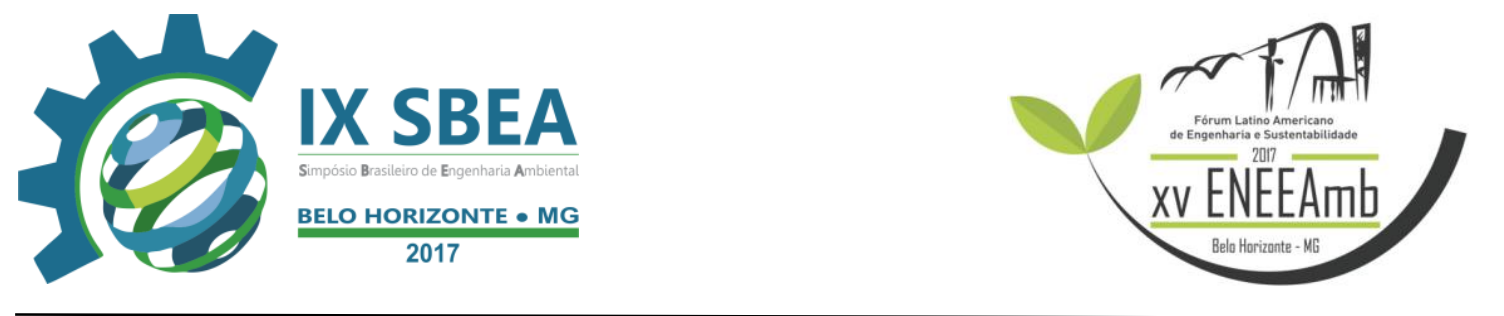

O terceiro dia de atividades, 22 de março, se comemora o Dia Mundial da Água. A data foi criada pela ONU (Organização das Nações Unidas) em 1992, considerando a preocupação da entidade com esse recurso natural tão precioso e essencial para a vida no planeta. Neste mesmo dia, a ONU também divulgou um importante documento: a "Declaração Universal dos Direitos da Água" no qual apresenta uma série de medidas, sugestões e informações que tem por finalidade despertar tanto na população como nos governos a consciência pela preservação e uso racional da água. Logo, o terceiro tema escolhido para ser trabalhado com as crianças foi a Água.

A principal atividade foi a confecção de cartazes, que enfatiza a importância da água para a vida, além de formas de economia e reaproveitamento (Figuras 3). Antes, a temática foi apresentada e as crianças foram levadas a refletir e expor suas experiências sobre o assunto, que envolviam o consumo racional, desperdício e proposição de soluções reais para os problemas relacionados.

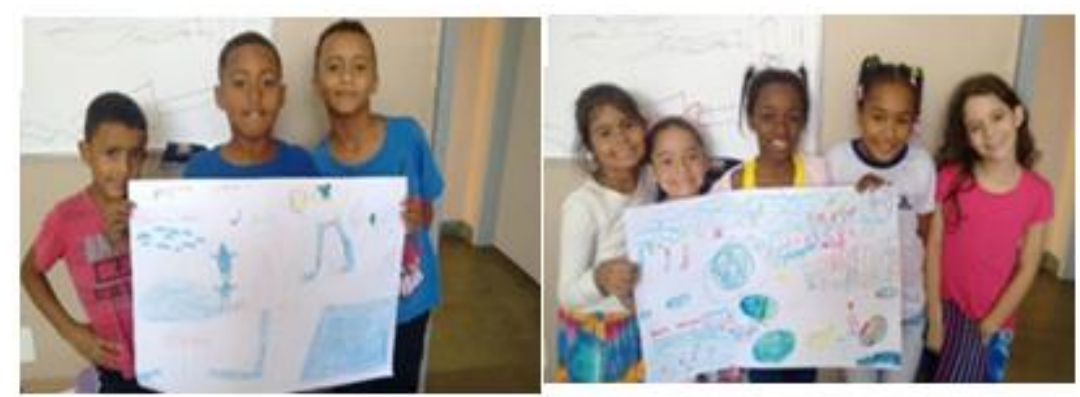

Figura 3: Cartazes alusivos ao Dia Mundial da Água confeccionados na atividade 3.

Fonte: arquivo Engenheiros sem Fronteiras - JF

Seguindo a semana de atividades, foi realizada a oficina de brinquedos confeccionados com garrafas PET, em que as crianças puderam confeccionar bilboquês. Para a confecção de cada bilboquê é necessária uma garrafa PET, preferencialmente de dois litros, barbante e tinta para decorar. A atividade tem o intuito de desenvolver o senso 
de reaproveitamento de materiais, muitas vezes descartados de forma incorreta, estimulando a criatividade e a coordenação motora das crianças (Figura 4).

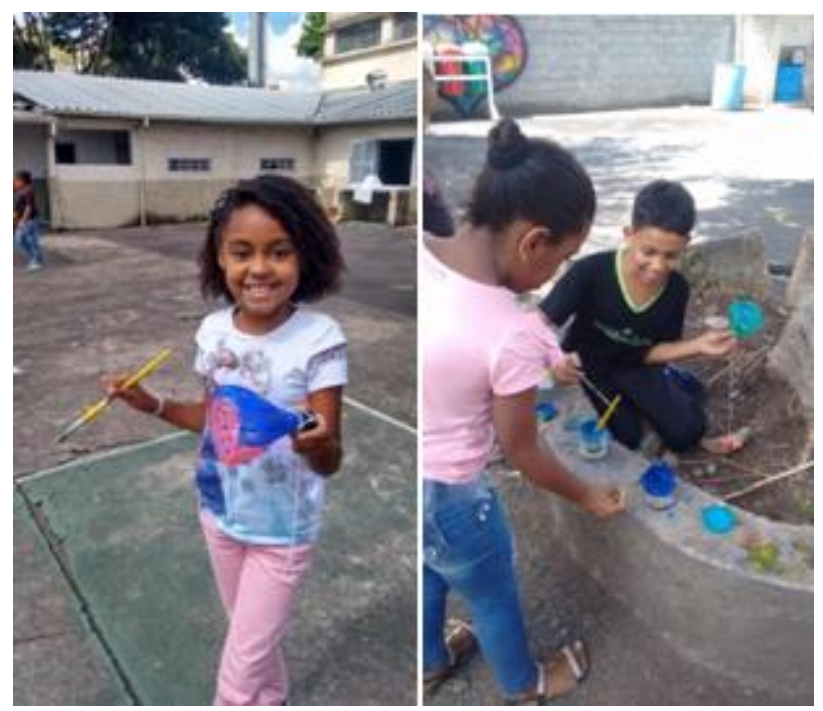

Figura 4: Crianças da fundação Pe. João Emílio na Oficina de Brinquedos

Fonte: arquivo Engenheiros sem Fronteiras-JF

Para o encerramento das atividades foi organizada uma apresentação, feita pelas crianças da Instituição, com textos e músicas abrangendo a temática abordada durante o projeto, além da apresentação de um vídeo contendo imagens das atividades desenvolvidas durante toda a semana (Figura 5). O encerramento contou com a presença dos pais e/ou responsáveis das crianças, dos professores e funcionários da instituição, tendo como objetivo demonstrar o envolvimento das crianças com o projeto e os conhecimentos adquiridos por elas. 

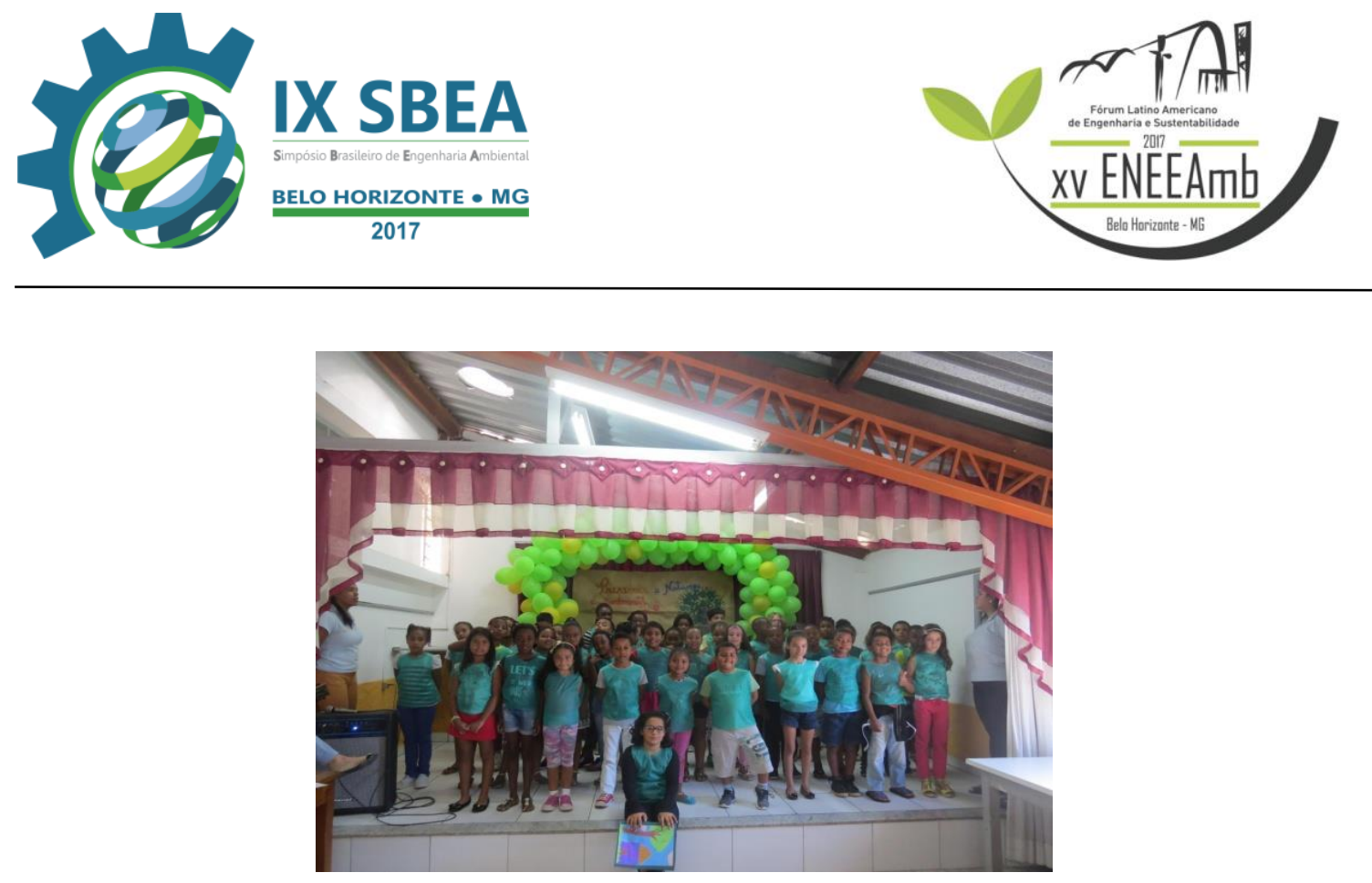

Figura 5: Apresentação de encerramento das atividades.

Fonte: arquivo Engenheiros sem Fronteiras-JF

\section{CONCLUSÕES/RECOMENDAÇÕES}

Durante a realização do projeto foi observado que ainda há muito a se fazer para modificar os hábitos de toda população, em relação às diversas atividades cotidianas que podem colaborar com a preservação ambiental, tais como separação e descarte de resíduos sólidos, consumo não excessivo de água, entre outras. Porém, percebeu-se que crianças podem ser e já são, agentes multiplicadores e transformadores das próprias famílias, contribuindo para desconstrução de antigos costumes e conceitos. Com isso, a introdução da educação ambiental nos primeiros anos de vida de um ser humano pode contribuir muito para que este se torne um adulto mais consciente, participativo e ciente do seu papel de cidadão. Aspectos notados junto às crianças do Instituto João Emílio, como entusiasmo, disposição e a facilidade de aprender e discutir de forma crítica assuntos relacionados ao meio ambiente, também confirmaram a importância de capacitá-los desde o ensino fundamental, com conteúdo de educação ambiental. 


\section{REFERÊNCIAS BIBLIOGRÁFICAS}

ELALI, G.A.O ambiente da escola - o ambiente na escola: uma discussão sobre a relação escola-natureza em educação infantil. Estudos de Psicologia. 2003, 8(2), 309319

ESF-Brasil: Quem somos. Disponível em: http://esf-brasil.org/. Acesso em: 18 abr. 2017. PEDRINI, A.; COSTA, E.A.; GHILARDI, N.Percepção ambiental de crianças e préadolescentes em vulnerabilidade social para projetos de educação ambiental.Ciência\& Educação, v. 16, n. 1, p. 163-179, 2010

REIGADA, C.; REIS,M. F. C. T. Educação ambiental para crianças no ambiente urbano: Uma proposta de pesquisa-ação. Ciência \& Educação, v. 10, n. 2, p. 149-159, 2004

PUC-SP: Ecopolítica- Os direitos da água. Disponível em:http://www.pucsp.br/ecopolitica/documentos/seguranca/docs/declaracao_direitos_ag ua_onu.pdf. Acesso em: 26 maio 2017.

UN: World Water Day. Disponível em:http://www.worldwaterday.org. Acesso em: 26 maio 2017. 